\title{
Estimation of maximum power generated from CIGS photovoltaic modules under non-uniform conditions
}

\author{
Mabel U. Olanipekun ${ }^{\mathrm{a} *}$, Josiah L. Munda ${ }^{\mathrm{a}}$, Hens-Wien G. Chen ${ }^{\mathrm{a}}$, A. S Kumar ${ }^{\mathrm{a}}$ \\ ${ }^{a}$ Tshwane University of Technology, Department of Electrical Engineering, Pretoria, 0001, South Africa
}

\begin{abstract}
In this work, Artificial Neural Network (ANN) is used to predict the output power generated from a single junction $\mathrm{Cu}(\mathrm{In}, \mathrm{Ga}) \mathrm{Se}_{2}$ (CIGS) thin-film photovoltaic (PV) module by investigating the effect of the number of input variables on the estimated accuracy. The neural network structure used is based on using cell temperature and irradiation and two electrical parameters; the open circuit voltage and the short circuit current of the CIGS thin film PV module as its inputs with the predicted maximum power generation as its output. The proposed method uses the manufacturer's data of the single junction CIGS thin film PV module NWCIGS-96. From the simulation results using ANN tools the average values for coefficient of determination $\left(R^{2}\right)=0.8882$, correlation coefficient $(C C)=0.9424$, relative mean square error $(\mathrm{RMSE})=22.9034$ and mean absolute error $(\mathrm{MAE})=19.0016$
\end{abstract}

Keywords: Artificial Neural Network, Estimated Power, PV module, Irradiation, Module Temperature, Open Circuit voltage, Short Circuit Current.

\section{Introduction}

Solar energy has a wide range of applications from rural energy electrification to satellite communication. Its penetration has increased significantly due to global environmental reasons and sustainable energy development.

With the increasing demands for energy and the threat of a looming energy crisis, South Africa is ideally positioned to take advantage of solar energy as an alternative energy source. As indicated in the 2010 Integrated Resource Plan (IRP), South Africa has set generation targets for technologies of 8400MW of Photovoltaic (PV) but currently, about only 632MW of PV have been procured in the first round of the Departments of Energy's (DOE) Renewable Energy Independent Power Producers Procurement Programme (REIPPP) [1][2].

However, since solar energy obtained from a solar PV module is not constant, a major challenge will be to maximize the use of solar energy due to the unpredictability of the output power of the PV modules from the resulting variations in irradiance levels and cell temperature.

The extracted power from the PV system is a function of the PV array voltage and current. The estimated output energy of PV modules will be beneficial to the investment calculation of a solar energy system [3] especially in optimizing the operating condition of the PV system [4].

Most solar PV modules produced for terrestrial applications are made from crystalline silicon solar cells. Thin-film solar modules based on amorphous silicon (a-Si), cadmium telluride (CdTe), Copper Indium Selenide (CIGS) and Gallium Arsenide (GaAs) are gaining a strong foothold in the world PV market with PV modules from thin film technology becoming the most promising. Thin film technology offers a number of advantages. Its test sequence for the design qualification and type approval is described in IEC 61646 [5].

\footnotetext{
* Manuscript received August 4, 2013; revised November 4, 2013.

Corresponding author. Tel.: +27 12382 4824; E-mail address: OlanipekunMU@tut.ac.za.
} 
Artificial Neural Network (ANN) is used for modeling PV modules in two ways; either to predict the equivalent circuit parameter, or to generate the I-V curves of PV modules under different weather conditions [7]. ANN has also been used to estimate the maximum power generation from a PV module by using the environmental information, such as, irradiance level, temperature and wind velocity [6]. An advanced ANN based model of a PV module was developed to predict output power accurately and to take into consideration the operating conditions. However, due to the uncertainty in cell temperature measurement, the ambient temperature (instead of the module temperature) was used as input parameter to the models [7].

There are several benefits of using ANN, these include: it does not require a prior knowledge of the internal system parameters; involves less computational effort and provides a compact solution for multivariable problems [8].

This paper proposes a 3-layer ANN architecture, which is used to predict the power generated by a CIGS thin film PV module for a typical winter period in Pretoria, South Africa. The inputs to the network are the non-uniform irradiance level, module temperature, open circuit voltage and the short circuit current (Isc) with the output signal as the predicted maximum power from the PV module.

\section{Choice of Photovoltaic Module}

Thin Film solar cells are made by depositing one or more thin layers of photovoltaic material on a substrate. There are different categories of Thin-film solar cells, depending on the PV material used. These include: amorphous silicon (a-Si), cadmium telluride (CdTe), copper indium gallium selenide (CIS or CIGS), dye sensitized solar cells (DSC) and other organic solar cells. Thin film solar cells compared to other solar cells have the highest efficiency of about $12-20 \%$ based on $\mathrm{Cu}(\mathrm{InGa}) \mathrm{Se}_{2}$ [5].

\section{Basic Model of thin Film Cigs PV Module}

The double diode model (DEM), also known as the five-parameters model, is a more appropriate model used for a CIGS PV module and is used to describe its current-voltage (I-V) characteristics under light conditions[6].

$$
I=-I_{p h}+I_{s 1}\left(\left[\exp \left(\frac{q V_{D}}{k T}\right)-1\right]+I_{s 2}\left[\exp \left(\frac{q V_{D}}{2 k T}\right)-1\right]+\frac{V_{D}}{R_{S H}}\right)
$$

where, $V_{D}=V-I R S$

$$
V_{o c, 0}^{c}=\frac{V_{o c, 0}^{m}}{N_{s m}}
$$

where $\mathrm{V}_{\text {moc.0 }}$ is the open circuit voltage of the PV module, Ns = number of cells in series in PV module

$$
\begin{gathered}
I s c(T c)=I s c 0\left[\frac{G}{G o}\right]\left(1+\alpha_{i s c}\left(T_{c}-T_{o}\right)\right) \\
V_{o c}(T)=V_{o c, 0}^{c}+N_{s m} \delta(T c) \operatorname{In}(G)+\beta_{V o c .0} G(T c-T a) \\
\text { and } T c=\left(273+T o+\frac{N O C T-20}{0.8}\right) G
\end{gathered}
$$

where $\mathrm{G}_{\mathrm{o}}=$ reference irradiance, $1000 \mathrm{~W} / \mathrm{m}^{2}$ 
$\mathrm{T}_{\mathrm{o}}=$ reference temperature, $25^{\circ} \mathrm{C}$

$\mathrm{T}_{\mathrm{c}}=$ Temperature of the cell

$\mathrm{I}_{\mathrm{sc}, 0}=$ Short circuit current at standard test condition

$\alpha_{i s c}=$ temperature coefficient at Isc $=-0.01 \pm 0.04$

$\beta_{\mathrm{voc}}=$ temperature coefficient at $\mathrm{Voc}=0.3 \pm 0.04$

Like other types of solar cells, the thin film solar cells generate photocurrents by photo-generation (or release of electrons) and charge separation (or current creation).

For this work, two parallel connected NW CIGS-96 photovoltaic modules, each consisting of $118 \mathrm{CIG}$ $\left(\mathrm{Cu}(\mathrm{IN}, \mathrm{Ga}) \mathrm{Se}_{2}\right.$ cells connected in series are used. Each module provides $96 \mathrm{~W}$ of maximum power and its electrical specification is shown in Table 1 below

Table 1. Electrical characteristics data of NW CIGS-96 PV module

\begin{tabular}{ll}
\hline Maximum Power $\left(\mathrm{P}_{\max }\right)$ & $96 \mathrm{~W}$ \\
Voltage at Maximum Power $\left(\mathrm{V}_{\mathrm{mpp}}\right)$ & $61.54 \mathrm{~V}$ \\
Current at Maximum Power $\left.\mathrm{I}_{\mathrm{mpp}}\right)$ & $1.54 \mathrm{~A}$ \\
Open Circuit Voltage $(\mathrm{Voc})$ & 77.10 \\
Short Circuit Current $(\mathrm{Isc})$ & $1.69 \mathrm{~A}$ \\
Module Size & $1190 \times 630 \mathrm{~mm}$ \\
\hline
\end{tabular}

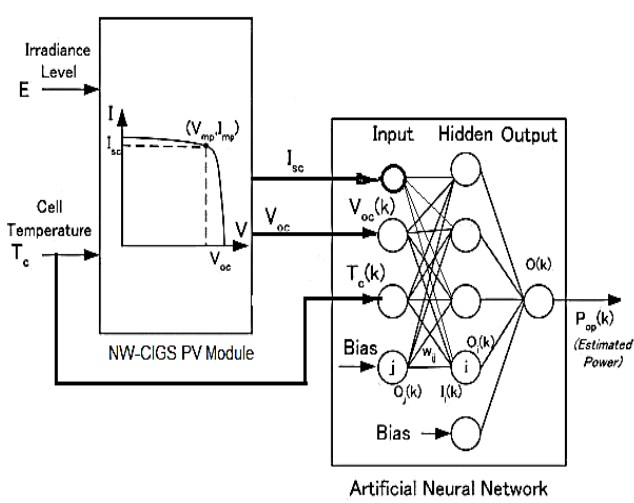

Fig. 1. Proposed artificial neural network for the CIG-thin film PV module

\section{Configuration of the Neural Network}

A typical neural network has three layers; input, hidden and output layers. Each layer consists of neurons which are connected to the next layers. There are also three basic parameters associated with ANN. These are the learning rate $(\mathrm{L})$, a number between 0 and 1 which indicates how much the weight changes to make effect on each pass, the momentum rate $(\mathrm{M})$ and the epoch.

ANN using Multilayer Perceptron is used to predict the output power generated for the CIGS thin-film PV modules under natural non-uniform irradiance level and module temperature. In the training process, the output power generated is used as the target output using a sigmoid activation function.

The input layer consists of five nodes for irradiation, module temperature $\left(\mathrm{T}^{\mathrm{o}} \mathrm{k}\right)$, open circuit voltage $\left(\mathrm{V}_{\mathrm{oc}}\right)$, and short circuit current $\left(\mathrm{I}_{\mathrm{sc}}\right)$. A bias signal of 1.0 is set to improve the learning speed; the hidden layer has six nodes, which also include one bias node and the output layer has one node for predicting the maximum power.

Data collected from the photovoltaic system set up on the roof top of Building 6, Tshwane University of Technology, Pretoria West, South Africa (Lat. $37.094^{\circ}$, Long. $-2.358^{\circ}$ and elevation $499.0 \mathrm{~m}$ a.s.l) for a typical winter season was used to evaluate the proposed configuration of the neural network. The measured data was taken between $12.00 \mathrm{hr}$ and $21.00 \mathrm{hr}$. (9 hours) each day from 16 June to 4 July 2013. 
For both hidden and output layers, the sigmoid activation function is used for the input-output characteristics of the nodes with each node $i$ in the hidden layer and the output $O_{i}(\mathrm{k})$ being expressed as [12].

$$
\mathrm{O}_{\mathrm{j}}(\mathrm{k})=\frac{1}{1+\mathrm{e}^{-\mathrm{I}_{\mathrm{i}}(k)}}
$$

The term $I_{i(\mathrm{k})}$ in equation (7) above is the input signal to node $i$ at the $k$-th sampling while $I_{i(\mathrm{k})}$ is the weighted sum of the input nodes described by:

$$
I_{i}(k)=\sum_{j} w_{i j}(k) O_{j}(k)
$$

where $w i j=$ connection weights from node $j$ to node $i$ and $\mathrm{O}_{\mathrm{j}}(\mathrm{k})$ is the output from node $j$.

Most ANNs use feed-forward neural network (FFNN) also known as Multilayer Perceptron (MLP) with Back Propagation Learning (BPL) algorithm. The back propagation learning algorithm is based on the gradient descent technique which involves the maximization of the network cumulative error. The equation of the sum of the squared error is expressed as:

$$
\mathrm{E}_{\mathrm{e}}=\sum\left[t(k)-\mathrm{O}_{\mathrm{i}}(\mathrm{k})\right]^{2}
$$

where

$t(\mathrm{k})=$ the reference (target) network output at the $\mathrm{k}^{\text {th }}$ sample.

$O_{i}(\mathrm{k})=$ the actual network output at the $\mathrm{k}^{\text {th }}$ sample

$\mathrm{N}=$ number of training pattern or epoch

\section{ANN based Prediction of Maximum Power of a CIGS PV Module}

The Multilayer perceptron MLP training function is used to predict the maximum power produced by the CIGS PV module. Levenberg Marquardt (LM) algorithm was used to minimize the Mean Square Error (MSE) of the MLP adopted. Four ANN models (Table 2) of different input variables are proposed

\begin{tabular}{|c|c|c|c|c|}
\hline \multicolumn{5}{|c|}{ Input Parameters for the different models } \\
\hline $\begin{array}{l}\text { Model I (CIG-PV) } \\
\text { (4-input parameters) }\end{array}$ & maximum irradiance $(\mathrm{G})$ & module temperature $\left(\mathrm{T}^{\circ} \mathrm{k}\right)$ & open circuit voltage $\left(v_{o c}\right)$ & $\begin{array}{l}\text { short circuit } \\
\text { current }\left(i_{s c}\right)\end{array}$ \\
\hline $\begin{array}{l}\text { Model II (CIG-PV1) } \\
\text { (2-input parameters) }\end{array}$ & maximum irradiance $(\mathrm{G})$ & module temperature $\left(\mathrm{T}^{\circ} \mathrm{k}\right)$ & - & - \\
\hline $\begin{array}{l}\text { Model III (CIG-PV2) } \\
\text { (3-input parameters) }\end{array}$ & open circuit voltage $\left(v_{o c}\right)$ & short circuit current $\left(i_{s c}\right)$ & - & - \\
\hline $\begin{array}{l}\text { Model IV (CIG-PV3) } \\
\text { (3-input parameters) }\end{array}$ & maximum irradiance $(\mathrm{G})$ & module temperature $\left(\mathrm{T}^{\circ} \mathrm{k}\right)$ & open circuit voltage $\left(v_{o c}\right)$ & - \\
\hline $\begin{array}{l}\text { Model V (CIG-PV3) } \\
\text { (3-input parameters) }\end{array}$ & maximum irradiance $(\mathrm{G})$ & module temperature $\left(\mathrm{T}^{\circ} \mathrm{k}\right)$ & short circuit current $\left(i_{s c}\right)$ & - \\
\hline
\end{tabular}
for the estimated power output (EP):

Table 2. ANN models used and their input parameters

\section{Performance Analysis of the ANN}

Six different statistical indicators are used to evaluate the performance of the network. These are the mean square error (MSE), root mean square error (RMSE), mean absolute error (MAE), mean absolute percentage error (MAPE), correlation coefficient (CC), root relative mean square and coefficient of determination (R2) [7],[13]:

(i) Correlation coefficient

$$
\mathrm{CC}=\frac{\sum_{\mathrm{i}=1}^{N}\left(\mathrm{y}_{1}-\bar{y}\right) \cdot\left(x_{1}-\bar{x}\right)}{\left[\sum_{i=1}^{N}\left(y_{1}-\bar{y}\right)^{2}\right]\left[\sum_{i=1}^{N}\left(x_{1}-\bar{x}\right)^{2}\right]}
$$


where $y_{i}=i^{\text {th }}$ estimated value

$x_{i}=i^{\text {th }}$ measured value

$\bar{y}=$ estimated mean value

$\bar{x}=$ measured mean value

$\mathrm{N}=$ number of analyzed data

(ii) $\mathrm{MAE}=\frac{1}{N} \sum_{i=1}^{N}\left|y_{i}-x_{i}\right|$

(iii) $\mathrm{RMSE}=\left\{\sum_{\mathrm{i}=1}^{N}\left(\mathrm{y}_{\mathrm{i}}-x_{1}\right)^{2} / N\right\}^{1 / 2}$

(iv) $\mathrm{MSE}=\frac{1}{N} \sum_{i=1}^{N}\left(y_{i}-x_{i}\right)^{2}$

(v) $R^{2}=\frac{\sum_{i=1}^{N}\left(y_{i}-x_{i}\right)^{2}}{\sum_{i=1}^{N}\left(y_{i}-\bar{y}_{i}\right)^{2}}$

(vi) $\quad \mathrm{MAPE}=\frac{1}{N} \sum_{i=1}^{N}\left|\frac{y_{i}-x_{i}}{x_{i}}\right|$

The other statistical indicators are expressed in percentage error. These are the relative absolute error (RAE) and the root relative square error (RRSE).

$$
\begin{array}{r}
\text { (vii) } \mathrm{RAE}=\frac{\left|y_{1}-x_{1}\right|+\cdots+\left|y_{N}-x_{N}\right|}{\left|\bar{x}-x_{1}\right|+\cdots+\left|\bar{x}-x_{N}\right|} \\
\text { (viii) } \operatorname{RRSE}=\frac{\left(y_{1}-x_{1}\right)^{2}+\cdots+\left(y_{N}-x_{N}\right)^{2}}{\left(\bar{x}-x_{1}\right)^{2}+\cdots+\left(\bar{x}-x_{N}\right)^{2}}
\end{array}
$$

\section{Results and Discussion}

A training set of the ANN with Multilayer Perceptron (MLP) is considered with two hidden layers using the following parameters (Table 3):

(i) Learning Rate $(\mathrm{L})=0.3$, Momentum $(\mathrm{M})=0.2$, No of Epoch $(\mathrm{N})=500$

Table 3: Evaluation Result on training set using Multilayer Perceptron with 2-two hidden layers

\begin{tabular}{llllll}
\hline Parameters & \multirow{2}{*}{ Model 1 } & Model II & Model III & Model IV & Model V \\
& & & & & \\
\hline Time to build model & $0.08 \mathrm{sec}$ & $3.2 \mathrm{sec}$ & $0.26 \mathrm{sec}$ & $0.12 \mathrm{sec}$ & $0.07 \mathrm{sec}$ \\
$\mathrm{CC}$ & 0.9424 & 0.9356 & 0.8608 & 0.9439 & 0.9343 \\
MAE & 19.0016 & 18.3875 & 13.0725 & 18.6513 & 17.534 \\
RMSE & 22.9034 & 22.3774 & 20.0577 & 22.3415 & 21.8592 \\
RAE (\%) & 57.8121 & 55.9438 & 39.474 & 56.7465 & 53.347 \\
RRSE (\%) & 58.5724 & 57.2273 & 50.9291 & 57.1354 & 55.902 \\
$\mathrm{R}^{2}$ & 0.8882 & 0.8753 & 0.8349 & 0.8910 & 0.873 \\
$\mathrm{~N}$ & 126 & 126 & 126 & 126 & 126 \\
\hline
\end{tabular}


The graphs of the estimated power against the measured output power produced by the NWCIGS PV module for each of the models described in Table 2 above is shown in figures 1.0 to 5.0.

Another set of Data taken from 5 July to 21 July 2013 was used for testing the ANN and to validate the results from the ANN models (see table 4 below). Though Model IV has the highest $\mathrm{R}^{2}$ and CC when compared with other models, Model 1 which has all parameters in the inputs nodes gave the best results. Hence, Model 1 was adopted for this work as it has the highest MAE, RAE, RRSE compared to other models. This shows that using the complete input parameters to model the PV estimated power output of the NWCIGS PV modules gives a better prediction.

Table 4: Data Set from 5 July to 21 July 2013 for testing the ANN

\begin{tabular}{llll}
\hline Results/ Parameters & Training Set & Test Set & Validation \\
\hline C & 0.9416 & 0.9356 & 0.8608 \\
MAE & 19.0094 & 18.3875 & 13.0725 \\
RMSE & 22.9723 & 22.3774 & 20.0577 \\
RAE (\%) & 57.8358 & 55.9438 & 39.474 \\
RRSE (\%) & 58.7486 & 57.2273 & 50.9291 \\
N & 126 & 124 & 126 \\
\hline
\end{tabular}

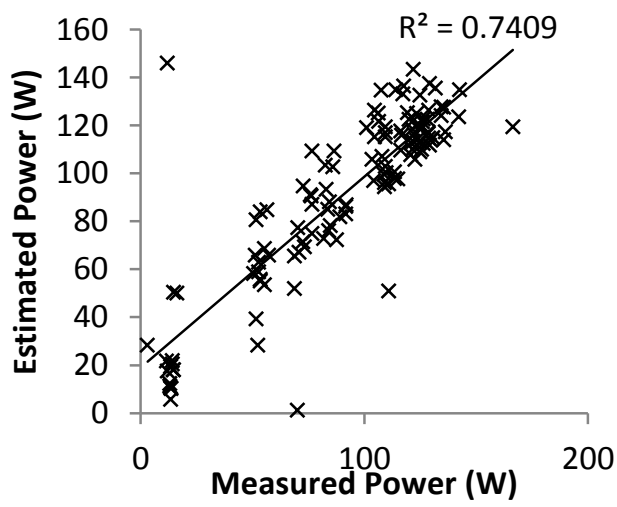

Fig. 2. Graph of Measured Power against Estimated Power for ANN Model 1 CIG PV Module

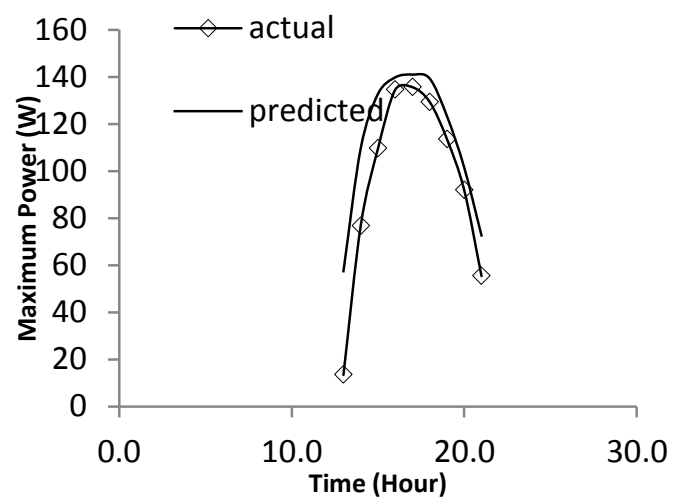

Fig. 3. Graph of maximum power output against time (Hour) for ANN Model I CIG PV module

\section{Conclusion}

The paper dealt with estimation of maximum power generated from a CIGS photovoltaic module 
under non-uniform conditions using different architectures of ANN models. The input variables are the module temperature, insolation, open circuit voltage and the short circuit voltage of the module while the output is the measured power. The performances of the models were measured in terms of $\mathrm{R}^{2}, \mathrm{CC}$, MSE and RMSE amongst other statistical tools. The architecture that gives the best performance is Model 1, with all the four input variables. It can be concluded that ANN can be used to predict the maximum power generated from a NWCIGS PV module using the double diode electrical equivalent (DEM) model.

\section{References}

[1] Deng F, Su G, Liu C, Wang Z. Global solar radiation modeling using the artificial neural network technique. in Proc. Power and Energy Engineering Conference, Chengdu, 2010: 1-5.

[2] Blanckeberg G. (June 2013). PV Industry set for growth. 25degrees in Africa [Online] Available: http://www.25degrees.net/index.php/component/option,com_zine/id,1527/view,article/

[3] González-Longatt FM. Model of Photovoltaic Module in Matlab ${ }^{\mathrm{TM}}$. in Proc. 2 DO Congreso Iberoamericano De Estudiantes De Ingeniería Eléctrica, Electrónicay computación (II CIBELEC 2005) Venezuela, 2006:1-5

[4] S. W. Gassing SW, Muslimin Z, Tahir Z, Karatepe E, Hiyama T. Three layered feed-forward neural network based estimation of output power and energy on photovoltaic (pv) modules. in proc. of 3rd Makassar International Conference on Electrical Engineering and Informatics Indonesia, 2012:93-98.

[5] Kandil KM, Altouq MS, Al-asaad AM, Alshamari LM, Kadad IM, Ghoneim AA. Investigation of the performance of CIS photovoltaic modules under different environmental conditions. Smart Grid and Renewable Energy, 2011; 2:375-387

[6] Werner BA, Prorok M. Analysis of the applicability of the diode equivalent model for GIGS thin-film photovoltaic modules. IEEE International Students and Young Scientists Workshop, Photonics and Microsystems, 2006.

[7] Hiyama T, Kitabayashi K. Neural network based estimation of maximum power generation from PV module using environmental information. IEEE Trans on Energy Conversion, 1997; 12(3): 241- 247.

[8] Karamirad M, Omid M, Alimardani R, H. Mousazadeh H, Heidari SN. ANN based simulation and experimental verification of analytical four- and five-parameters models of PV modules. Simulation Modelling Practice and Theory, February 2013;34:8698.

[9] Prorok M, Werner M, Zdanowicz M. Applicability of equivalent diode models to modeling various thin-flim phtovoltaic (PV) modules in a wide range of temperature and irradiance condition. Internet Journal Electron Technology, 2005/2006; 37/38(6):1-4.

[10] JJohansson J, Zimmermann U, Edoff M. Modelling and optimization of CIGS modules. in Proc. of 22 $2^{\text {nd }}$ European Photovoltaic Solar Energy Conference, Milan, Italy; 2007:1922-1925.

[11] Brofferio SC, Antonini A, Galimberti G, Galeri D. A method for estimating and monitoring the power generated by a photovoltaic module based on supervised adaptive neural networks. in Smart Measurements for Future Grids (SMFG), Bologna: 2011:148-153.

[12] Jiang Y, J. Qahouq JAA, Batarseh I. Improved solar PV cell MATLAB simulation model and comparison. in Proc. of IEEE International Symposium on Circuits and Systems, Paris, 2010:2770-2773.

[13] Hiyama ST, Karatepe E. Feasibility of artificial neural network for maximum power point estimation of non crystalline-si photovoltaic modules intelligent system applications to power systems. in Proc. Intelligent Systems Applications for Power System (ISAP), Curitiba, 2009:1-6. 